\title{
MORPHOLOGICAL RESPONSES TO PITUITARY GONADOTROPHINS BY MOUSE OVARIES IN VITRO
}

\author{
MARGARET RYLE \\ United Birmingham Hospitals Department of Clinical Endocrinology, \\ Birmingham and Midland Hospital for Women, Birmingham 11 \\ (Received 26th September 1968, revised 29th January 1969)
}

\begin{abstract}
Summary. Ovaries from 16- to 17-day-old mice were cultured for 4 days in the presence of various concentrations of highly purified FSH and LH. Serial sections were prepared and parameters of all follicles with four or more layers of granulosa cells were measured. FsH significantly increased the total number of such follicles and in particular the number of small ones. It did not significantly increase the number of large ones although it markedly augmented the number of follicles with small antra. LH enlarged the mean follicle diameter by multiplying the number of large follicles while having no effect on the number of small ones, but it did not significantly increase the number of follicles with antra.
\end{abstract}

\section{INTRODUGTION}

Intact ovaries taken from 15- to 17-day-old mice respond in vitro to highly purified human follicle-stimulating hormone (FSH) by increasing their uptake of labelled thymidine (Ryle, 1969). Preliminary studies on 15-day mouse ovaries indicated that this was accompanied by follicle growth and that, as in vivo, FSH stimulated follicle cell mitosis. The rather contradictory results obtained when post-natal rat and mouse ovaries have been cultured with gonadotrophins have been summarized by Fainstat (1968). Stokłosowa \& Koziorowska (1966), using high concentrations of gonadotrophins, observed mainly tissue degeneration, and Bousquet (1967), who failed to obtain any response to bovine pituitary extract, stimulated mitosis of both stroma and follicle cells with rat pituitary explants. Variations in tissue maturity and gonadotrophin concentration and also the inclusion in the medium of serum, containing unknown amounts of various hormones, may account for the lack of agreement between the different experiments. Fainstat (1968) observed a great increase in mitotic figures in both follicle and stromal cells when rat ovaries were cultured in a serum-free synthetic medium with FSH (NIH-FSH-s2 and s3) or pregnant mare serum gonadotrophin. He did not, however, undertake detailed quantitative comparisons, nor did he examine any effects of luteinizing hormone ( $\mathbf{L H})$. The experiment 
described here provides quantitative evidence that both FSH and LH can produce morphological effects in vitro.

\section{MATERIALS AND METHODS}

Human pituitary gonadotrophins were used. The LH preparation contained less than 0.0003 i.u. FSH/i.u. LH by the mouse ovarian augmentation assay. The FSH preparation contained less than 0.012 i.u. LH/i.u. FSH by the rat ovarian ascorbic acid depletion assay. The general culture procedure was as before (Ryle, 1969) and the details correspond precisely to those of Experiment A in that paper: (i) a $4^{2}$ factorial design was used with $0,0 \cdot 05,0 \cdot 5$ and $5 \cdot 0$ i.u. of each hormone per dish containing $5 \mathrm{ml}$ of medium; (ii) the jars were gassed with $5 \% \mathrm{CO}_{2}$ in air; (iii) the ovaries were cultured for 4 days; (iv) the mice, 16 or 17 days old when dissected and weighing 6 to $7 \mathrm{~g}$, were derived from several litters. To ensure that the two ovaries exposed to each treatment were not from the same animal, the mice were allocated at random to two pools of eight. One ovary from each pool was then put in each of the sixteen culture dishes. Replicate dishes were not used owing to restricted facilities for gassing them. The ovaries of two additional mice were fixed at the time of dissection.

The ovaries were fixed for $1 \mathrm{hr}$ in Bouin's aqueous fixative and embedded in paraffin. Serial sections were cut at $7 \mu$ and stained with Ehrlich's haematoxylin and eosin. Each section was examined and those follicles having four or more layers of granulosa cells in the plane of the oocyte nucleolus were recorded and measured (unless more than $50 \%$ of the granulosa nuclei were pycnotic). Each of these follicles was classified as having four, five or more than five granulosa cell layers. The maximum diameter of the granulosa and the diameter at right angles to it were measured, and the mean diameter was calculated in $\mu$. Where more than $5 \%$ but less than $50 \%$ of the granulosa nuclei were pycnotic, this was noted. In addition, every ovary was scored for the extent of central pycnosis. Abnormal nuclei were common in the large oocytes but were disregarded. Follicles containing cavities entirely surrounded by granulosa cells which appeared in at least three consecutive sections were scored as having early antra; spaces between granulosa cells and oocytes were assumed to be abnormal and were ignored. While hormone effects on thecal and interstitial tissue might be expected, no attempt was made to measure them, although evidently thecal tissue must increase as the follicle grows.

The following parameters of the population of follicles with four or more layers were determined for each ovary: (i) total number of follicles; (ii) mean diameter; (iii) standard deviation of diameter; (iv) a 'follicle volume index' equal to one hundredth of the sum of the cubes of the diameters; (v) the number of follicles with early antra; (vi) the number and (vii) the proportion of follicles having 5 to $50 \%$ pycnotic nuclei. The effects of FSH and LH on each of these seven parameters and on the score for central pycnosis of the ovary were assessed by analyses of variance. In addition, in order to check the possibility of treatment effects on cell size, the mean diameters of those follicles having only four layers and of those having five layers were determined for each ovary and analyses of variance were carried out on these two sets of data. The variation 
between replicate ovaries was not an adequate estimate of experimental error, although the ovaries were from different mice, because it included no component for between-dish variation. Each treatment mean square has therefore been compared with the corresponding interaction mean square in the tests of significance.

\section{RESULTS}

Table 1 presents the analyses of variance and Table 2 the mean treatment effects for the first five parameters. FSH significantly increased the number of follicles, the volume index and the number with antra. It did not affect mean diameter or significantly change its standard deviation. LH also significantly

TABLE 1

ANALYSES OF VARIANGE FOR FIVE PARAMETERS MEASURED IN EAGH OVARY

\begin{tabular}{l|c|c|c|c|c}
\hline & & \multicolumn{4}{|c}{ Mean squares } \\
\cline { 2 - 6 } \multicolumn{1}{c|}{ Variation source } & d.f. & $\begin{array}{c}\text { No. follicles } \\
\text { with four or more } \\
\text { layers }\end{array}$ & $\begin{array}{c}\text { Mean follicle } \\
\text { diameter } \pm \text { S.D. }\end{array}$ & $\begin{array}{c}\text { Follicle } \\
\text { volume } \\
\text { index }\end{array}$ & $\begin{array}{c}\text { No.follicles } \\
\text { with antra }\end{array}$ \\
\hline Doses of FSH & 3 & $718 * *$ & $2 \cdot 6 \pm 1 \cdot 09$ & $184^{*}$ & $101 \cdot 7^{* * *}$ \\
Doses of LH & 3 & 298 & $48 \cdot 8 * * \pm 9 \cdot 28$ & $184 *$ & $9 \cdot 0$ \\
FSH $\times$ LH interaction & 9 & 118 & $9 \cdot 6 \pm 3 \cdot 30$ & 44 & $5 \cdot 8$ \\
Residual & 16 & 32 & $6 \cdot 6 \pm 1 \cdot 40$ & 11 & $3 \cdot 6$ \\
\hline
\end{tabular}

Significance: $*=5 \%, * *=2.5 \%, * * *=0.1 \%$.

Levels of significance are assessed by comparing the treatment mean squares with the interaction mean square.

TABLE 2

EFFECTS OF FSH AND LH ON MEAN PARAMETERS OF FOLLIGLE POPULATIONS

\begin{tabular}{cl|c|c|c|c}
\hline & $\begin{array}{c}\text { Mean no. follicles } \\
\text { with four or more layers }\end{array}$ & $\begin{array}{c}\text { Mean follicle } \\
\text { diameter } \pm S . D .(\mu)\end{array}$ & $\begin{array}{c}\text { Mean follicle } \\
\text { volume index }\end{array}$ & $\begin{array}{c}\text { Mean no. of } \\
\text { follicles with antra }\end{array}$ \\
\hline FSH (i.u./dish) & 0.0 & 22.0 & $77.6 \pm 9.11$ & 11.4 & 0.13 \\
& 0.05 & 19.5 & $76.9 \pm 9.18$ & 9.5 & 0.13 \\
& 0.5 & 29.3 & $78.3 \pm 9.35$ & 14.7 & 0.50 \\
& 5.0 & 40.6 & $77.6 \pm 9.93$ & 20.5 & 7.38 \\
LH (i.u./dish) & 0.0 & 26.8 & $76.2 \pm 8.68$ & 12.5 & 0.88 \\
& 0.05 & 22.6 & $75.9 \pm 8.51$ & 10.4 & 1.63 \\
& 0.5 & 25.4 & $77.1 \pm 9.54$ & 12.2 & 2.25 \\
& 5.0 & 36.6 & $81.2 \pm 10.87$ & 21.1 & 3.38 \\
S.E. of each mean & 3.8 & $1.1 \pm 0.64$ & 2.4 & 0.85 \\
\hline
\end{tabular}

increased the volume index although the upward trend in follicle number was not significant. It significantly increased mean follicle diameter, but not its standard deviation. LH did not significantly increase the numbers of follicles with antra.

The contributions of the two hormones are more clearly differentiated if their effects on the number of follicles of different sizes are examined separately. For 
Tables 3 and 4, three size categories were selected so that, with one unavoidable exception, every ovary had one or more follicles in each. FSH increased the number in the small category, but the apparent increase in the large category was not significant. LH, on the other hand, had no effect on the number in the small category but markedly increased the number in the large one. Neither hormone significantly increased the number of medium-sized follicles.

TABLE 3

ANALYSES OF VARIANGE FOR NUMBERS OF SMALL, MEDIUM AND LARGE FOLLICLES

\begin{tabular}{|c|c|c|c|c|}
\hline \multirow[b]{2}{*}{ Variation source } & \multirow[b]{2}{*}{ d.f. } & \multicolumn{3}{|c|}{ Follicle diameter } \\
\hline & & $\begin{array}{c}<74 \mu \\
\text { mean square }\end{array}$ & $\begin{array}{l}74 \text { to } 82 \mu \\
\text { mean square }\end{array}$ & $\begin{array}{c}>82 \mu \\
\text { mean square }\end{array}$ \\
\hline $\begin{array}{l}\text { Doses of FSH } \\
\text { Doses of } \mathrm{LH} \\
\text { FSH } \times \text { LH interaction } \\
\text { Residual }\end{array}$ & $\begin{array}{r}3 \\
3 \\
9 \\
16\end{array}$ & $\begin{array}{c}144 \cdot 7 * * \\
6 \cdot 7 \\
15 \cdot 6 \\
9 \cdot 0\end{array}$ & $\begin{array}{l}53 \cdot 0 \\
36 \cdot 3 \\
30 \cdot 8 \\
15 \cdot 6\end{array}$ & $\begin{array}{c}72 \cdot 3 \\
175 \cdot 3^{*} \\
28 \cdot 9 \\
5 \cdot 8\end{array}$ \\
\hline
\end{tabular}

* Significant at $2 \cdot 5 \%{ }^{* *}$ Significant at $1 \%$.

TABLE 4

EFFECTS OF FSH AND LH ON MEAN NUMBERS OF SMALL, MEDIUM AND LARGE FOLLICLES

\begin{tabular}{ll|c|c|c}
\hline & \multicolumn{3}{|c}{ Follicle diameter } \\
\cline { 3 - 5 } & & $<74 \mu$ & 74 to $82 \mu$ & $>82 \mu$ \\
\hline FSH (i.u./dish) & 0.0 & 6.9 & 8.5 & 6.6 \\
& 0.05 & 8.5 & 5.5 & 5.5 \\
& 0.5 & 11.9 & 9.3 & 8.1 \\
& 5.0 & 16.5 & 11.8 & 12.4 \\
LH (i.u./dish) & 0.0 & 11.4 & 8.9 & 6.5 \\
& 0.05 & 10.4 & 7.9 & 4.4 \\
& 0.5 & 12.0 & 6.6 & 6.8 \\
& 5.0 & 10.0 & 11.6 & 15.0 \\
S.E. of each mean & 1.4 & 2.0 & 1.9 \\
& & & \\
\hline
\end{tabular}

The mean number of follicles with four or more layers per ovary in those fixed when the cultures were set up was twenty-five and the mean number with antra was two. There were no significant treatment effects on the number or proportion of follicles having 5 to $50 \%$ pycnotic nuclei, on the score for central pycnosis, or on the mean diameter of follicles with either four or five layers of granulosa cells.

\section{DISGUSSION}

The results suggest that both FSH and LH stimulated follicular growth in vitro. However, differences in the numbers of healthy follicles per ovary could arise from treatment effects on follicle survival. Some pycnotic tissue was found in all 
cultures and, in comparison with those fixed at dissection, most cultured ovaries appear to have lost follicles with antra. Yet the mean number of follicles counted in those fixed at dissection was of the same order as in those cultured without hormone and less than in those cultured with the highest doses. In addition, there was no significant treatment effect either on the number (or proportion) of partially pycnotic follicles or on the score for central pycnosis. These findings suggest that the hormones induced better growth, not simply better survival. Follicle growth could arise from both cell division and cell enlargement. There was no treatment effect on mean follicle diameter when only those follicles with four layers or only those with five layers were considered, so cell size was unaffected in the smaller follicles. Larger follicles could not be examined in this way as their cell layers could not be counted but cell size appeared to be as constant as in the smaller follicles. Since antral cavities were rare in most ovaries and were small relative to total volume, the recorded follicle dimensions are approximately related to granulosa cell number.

The larger quantity of follicular tissue (volume index) resulting from FsH stimulation corresponds to the increased uptake of thymidine occurring under the same conditions (Ryle, 1969). As recruitment to the smallest category was particularly marked, the mitotic rate must have been enhanced in those follicles with less than four layers. This agrees with the observation of greater mitotic frequency due to FSH even in one- to two-layered follicles (Fainstat, 1968). The minimum effective dose of FSH, between 0.5 and $5.0 \mathrm{i} . \mathrm{u}$./dish, is the same as in the parallel thymidine uptake experiment with 16- to 17-day mice. In 15-day ovaries, however, thymidine uptake was almost maximally stimulated by $0.5 \mathrm{i}$.u./dish. Whether this difference is due to size, maturity or slightly different culture procedures is as yet uncertain.

LH did not consistently stimulate thymidine uptake and had no significant effect in the parallel experiment. Since it increased mean follicle diameter, while having no effect on the number of follicles in the smallest category, it must have preferentially stimulated further growth in those which had already reached a certain minimum size. As the number of follicles in the 'medium' and 'small' categories did not decline, sufficient recruitment into each must also have occurred to compensate for those promoted to the 'large' category. Presumably, ovaries initially lacking follicles of the required size and failing to develop enough of them in culture would respond to LH insufficiently to alter thymidine uptake significantly. Preliminary morphological observations on ovaries from smaller mice indicated no LH effect, perhaps for a similar reason.

Lostroh (1959) induced marked specifically follicular cell hyperplasia in 4-day mouse ovaries with oestrogens, as did Fainstat (1968) in rat ovaries. Since high concentrations of interstitial cell stimulating hormone induced mitosis in both thecal and follicular cells Lostroh suggested that it acted on the follicular cells by stimulating oestrogen synthesis in the theca. The low concentrations of LH used in the present work may have stimulated only those thecal cells which had reached a certain degree of maturity, and only those cells released enough oestrogen for the induction of granulosa mitosis.

The FSH effect on antrum formation is not simply related to follicle size for LH markedly increased the number of large follicles, yet had no significant 
effect on antrum frequency. Moreover, with 12.5 i.u. FSH/dish, similar cavities occur even in four-layered follicles (Ryle, unpublished). At present, there is no indication of how the stimulation of antrum formation is related to the stimulation of granulosa mitosis.

\section{ACKNOWLEDGMENTS}

I am indebted to Dr A. C. Crooke for his constant encouragement, to Dr W. R. Butt and Dr A. S. Hartree for the supplies of FSH and LH, to Mr P. V. Bertrand for much statistical help and to Miss M. Wardill and Miss M. Smith for skilled technical assistance. The work was supported by a grant from the Ford Foundation.

\section{REFERENCES}

Bousquet, J. (1967) Culture organotypique de fragments d'ovaire de ratte: action de facteurs gonadotropes hypophysaires. C.r. Séanc. Soc. Biol. 161, 778.

FaINStar, T. (1968) Organ culture of postnatal rat ovaries in chemically defined medium. Fert. Steril. $19,317$.

LostroH, A. J. (1959) The response of ovarian explants from post-natal mice to gonadotrophins. Endocrinology, 65, 124.

RYLE, M. (1969) A quantitative in vitro response to follicle-stimulating hormone. F. Reprod. Fert. 19, 87.

Stokzosowa, S. \& Koziorowska, J. (1966) Effect of hormones on ovaries cultured in vitro. Zoologica Pol. $16,139$. 